\title{
Abstinence Education Changes Perceptions of Middle School Students
}

\author{
Tary J. Tobin ${ }^{1}$, Cindy Bankston² \\ ${ }^{1}$ College of Education, University of Oregon, Eugene, Oregon, USA \\ ${ }^{2}$ Northwest Family Services, Portland, Oregon, USA \\ Email: ttobin@uoregon.edu
}

How to cite this paper: Tobin, T. J., \& Bankston, C. (2017). Abstinence Education Changes Perceptions of Middle School Students. Creative Education, 8, 2400-2411. https://doi.org/10.4236/ce.2017.815164

Received: November 10, 2017

Accepted: December 8, 2017

Published: December 11, 2017

Copyright (c) 2017 by authors and Scientific Research Publishing Inc. This work is licensed under the Creative Commons Attribution International License (CC BY 4.0).

http://creativecommons.org/licenses/by/4.0/

\begin{abstract}
Abstinence education lessons were designed to address teen pregnancy and sexually transmitted infection (STI) among adolescent youth. A community nonprofit organization with extensive experience in abstinence education trained youth leaders and high school students to collaborate with public school health education teachers. The lessons were based on Promoting Health Among Teens! [PHAT] Abstinence-Only, School Edition (Jemmott, Jemmott, \& McCaffree, 2014). Originally developed for use in schools with a high proportion of African Americans, they were adapted for use in schools with a high proportion of Latinos. Over 1000 students from nine middle schools in the northwest part of the United States participated. Responses to pre- and post-intervention survey items were compared and indicated improvements in knowledge of the benefits of sexual abstinence and changes in attitudes toward abstinence. The outcomes of the It's Legit II: Promoting Health Among Teens! Project indicated that it was implemented well, received well, and had a beneficial effect.
\end{abstract}

\section{Keywords}

Abstinence Education, Adolescents, Community Agency and School Collaboration, High School Peer Leaders

\section{Introduction}

The purpose of this evaluation of a federally funded Competitive Abstinence Education (CAE) program in the United States was to assess a project designed to address teen pregnancy and sexually transmitted infection (STI) among adolescent youth by providing lessons intended to change perceptions and intentions. This project developed lessons for use in public schools serving mul- 
ti-cultural, diverse populations with many Hispanic/Latino youth. It was based on an evidence-based tool with demonstrated effectiveness in reducing early sexual initiation among African American youth, the Promoting Health Among Teens! [PHAT] Abstinence-Only, School Edition (Jemmott, Jemmott, \& McCaffree, 2014). Jemmott, Jemmott, \& Fong (2010: 9-10) conducted the foundational research and reported that "The results indicate that a theory-based abstinence-only intervention reduced self-reported sexual involvement among African American students in grades 6 and 7, a population at high risk of pregnancy and STIs, including HIV. The abstinence-only intervention compared with the health-promotion control intervention reduced by about $33 \%$ the percentage of students who ever reported having sexual intercourse by the time of the 24-month follow-up, controlling for grade, age, and intervention-maintenance condition. Although other studies have reported intervention-induced reductions in sexual intercourse among adolescents, this is the first randomized controlled trial to demonstrate that an abstinence-only intervention reduced the percentage of adolescents who reported any sexual intercourse for a long period following the intervention, in this case, 24 months after intervention".

This curriculum is age-appropriate at the middle school age level, which is a critical time and a time when youth are likely to be receptive to this message. Smith, Panisch, Malespin, \& Pereira (2017) found, in an evaluation of the effectiveness of abstinence education delivered to 5772 middle and high school students, that the program was more effective with younger boys than with older boys. Another reason for choosing this curriculum was that Goesling, Colman, Trenholm, Terzian, \& Moore (2014: 499), after a systematic review of abstinence education programs, called for more research to address "two main gaps $\cdots$ a lack of replication studies and the need for more research on Latino youth".

Northwest Family Services (NWFS), a nonprofit agency in Portland, Oregon, worked with public school health teachers to implement the project. NWFS already had considerable experience implementing abstinence education and serving areas with high needs, including a previous 2-year CAE program using the Heritage Keepers curriculum; four previous grants (each 5 years) from the Office of Adolescent Pregnancy Programs (OAPP, later transferred to the Office of Adolescent Health) for implementing abstinence education programs; and three Community Based Abstinence Education (CBAE) grants.

Risks for Sexually Active Teens

Although the teen pregnancy rate has been dropping in recent years, it still is a concern as the majority of teen mothers live in poverty. "In 2014, Hispanic adolescent females ages 15 - 19 had the highest birth rate (38 births per 1000 adolescent females), followed by black adolescent females (34.9 births per 1000 adolescent females) and white adolescent females (17.3 births per 1000 adolescent females)" (Office of Adolescent Pregnancy, 2016: 1). A related problem is sexually transmitted infections (STIs). STIs are widespread and rates have been increasing among youth in Oregon (Terry, 2017) and across the country: "In 2015, 
rates of the three most common reportable STIs-chlamydia, gonorrhea and syphilis-reached a record high level... [with] approximately 1.5 million reported cases of chlamydia."

Previous evaluations of abstinence education programs indicate that teachers implementing the program are more effective if they believe that abstinence from sexual activity outside of marriage is reasonable and possible (DeGaston, Jensen, Weed, \& Tanas, 1994). NWFS staff and peer leaders will be of this belief system and knowledgeable about practical ways of encouraging positive attitudes among youth about sexual abstinence. An interesting aspect of this project was the practical collaboration between public school health education teachers, whose training would have been in sex education with a focus on promoting the use of contraception based on the assumption that youth would not abstain, and abstinence education experts from a nonprofit agency in the community who trained high school peer leaders to assist in presenting the abstinence education lessons to middle school students. In this project the agency, NWFS, had well established relationships with schools, having offered a range of useful programs over the years (see http://www.nwfs.org/empowering-youth.html).

The Intervention

The intervention used strategies addressing the social and emotional well-being of the youth served, based on three compatible theories: 1) social learning theory (Bandura, 1977, 1997, 2004); 2) the theory of reasoned action (Ajzen \& Fishbein, 2005; Fishbein, 2008); and the related theory of planned behavior (Hartman, 2009; Romano \& Netland, 2008). All of these theories have provided a basis for successful change in health-related behaviors by developing skills that are protective factors. Social learning theory emphasizes the role of modeling in learning. Positive youth development principles provide a foundation for lessons to enhance self-efficacy, positive identity, and pro-social behaviors which are all protective factors associated with abstinent behavior. The related theories of reasoned action and planned behavior assume that an individual's behavior is determined by intentions resulting from attitudes, normative beliefs, and perceived behavioral control.

The PHAT curriculum is interactive, with a focus on positive goals, and has many lessons involving role plays, appropriate refusal skills, and discussion. Originally designed for use in schools with a high proportion of African Americans, it was adapted by NWFS for use in schools with a higher proportion of Latinos. Select Media offers guidance on how to adapt PHAT for use with different ages and different ethnic or racial groups, such as changing the names used in role plays to be culturally appropriate. NWFS, in previous abstinence education interventions, had developed dramas with input from the local Latino community and also had developed a program, with a manual (Fuller \& Bankston, 2002), for recruiting, training, supervising, and motivating high school students to help with middle school abstinence education and to serve as role models. The high school students led discussions and shared their experiences and advice in term of finding abstinence valuable and possible. Ferraro \& Pressler (2011), who 
found in a longitudinal study that compared academic achievement in 21 high schools with an abstinence education program with 21 schools without such programs, that students in the schools with the abstinence education program had better results academically. They suggest that this was because of the influence of the peer leaders who were trained to present the abstinence education lessons: "The PEERS [Peers Educating and Encouraging Responsible Sexuality] program is distinctive in that $\cdots$ high school students deliver the content. Perhaps the message 'abstain to attain', has more gravity when delivered by a fellow student than by an adult" (Ferraro \& Pressler, 2011: 234).

Another adaptation was the addition of multimedia projects in which students created visuals and other items illustrating their understanding of what they were learning, with talent, creativity, and quality being recognized as their posters and other items were displayed at school, online, and in the community, with prizes awarded for the most outstanding ones. NWFS maintained web sites with information for youth and parents.

Importance of Educational Goals

Abstinence education involves helping youth set goals, including goals to graduate from high school. Oregon has the worst graduation rate in the country and teen pregnancy is one of the top five reasons Oregon teens drop out of school. "While the national average reached a record high of 81.4 percent, the four-year graduation rate in Oregon was only 69 percent. Furthermore, Oregon hadn't improved from the year before, showing stagnation as the last remaining state with graduation rates lower than 70 percent" (Roth, 2015). According to Child Trends Databank (2017), by their senior year in highs school, about $49 \%$ of teens will be sexually active, and sexually active youth have lower levels of educational achievement, and more problems with substance abuse and depression, than youth who abstain. Youth who feel connected to school are more likely to delay initiation of sexual activity.

Post-intervention Survey Previously Related to Longer Term Outcomes

The Promoting Health Among Teens! Abstinence-Only, School Edition, (Jemmott et al., 2014) curriculum comes with a research based survey that measures changes from pre- to post-intervention in students' responses to questions about knowledge, attitudes, and perceptions that a two year follow up found to be associated with a reduced incidence of initiation of sexual activity: "The abstinence-only intervention reduced sexual initiation (risk ratio [RR], $0.67 ; 95 \%$ confidence interval [CI], 0.48 - 0.96). The model-estimated probability of ever having sexual intercourse by the 24 -month follow-up was $33.5 \%$ in the abstinence-only intervention and $48.5 \%$ in the control group. Fewer abstinence-only intervention participants (20.6\%) than control participants $(29.0 \%)$ reported having coitus in the previous 3 months during the follow-up period" (Jemmott et al., 2010: 152). Using the pre- and post-intervention survey, they found that the adolescents who received the Promoting Health Among Teens! Abstinence-Only Intervention believed more strongly that practicing abstinence would prevent pregnancy and HIV/AIDS $\cdots$ and reported weaker intentions of 
having sexual intercourse over the next three months than did those in the control group. They also believed more strongly that practicing abstinence would help them achieve their career goals than did those in the control group (from http://www.prweb.com/releases/2011/10/prweb8900706.htm). Knowing that the survey results were positively associated with a reduced incidence of initiation of sexual activity in research with a two-year follow-up was important because CAE grants provided limited funding for project process and initial outcome evaluation with no funds for research with longer term follow-ups. The pre- and post-intervention survey used in the evaluation of It's Legit II also included some other items of interest, including some from a survey developed for a randomized controlled trial developed by the Office of Adolescent Pregnancy Prevention which NWFS had previously found reliable and valid (Vincent, Xue, Tobin, \& Fuller, 2011).

Project Objectives

The project had objectives related to activities and to expected outcomes, including: 1) public school teachers, NWFS staff, and peer leaders working together to provide the PHAT curriculum for participating middle school students; 2) public school health teachers providing lessons with information on reproductive anatomy, fetal development, and STI prevention information; 3) lessons will increase perceptions that abstinence facilitates avoidance of risks for HIV/STI and unplanned pregnancy; 4) lessons related to abstinence will bolster positive attitudes and beliefs regarding abstinence; and 5) lessons will result in stronger intentions to practice abstinence, as measured by a pre- and post-intervention survey.

\section{Method}

\section{Settings and Participants}

The participating schools were located in urban, suburban, and rural areas of Multnomah and Clackamas Counties in Oregon. These counties had rapidly growing, low income ethnic populations that have high birth rates. The schools were in 3 different school districts: 1) Colton School District, 2) Oregon City School District, and 3) Gresham-Barlow School District.

A total of 2211 middle school students completed pre- and post-intervention surveys during the first and second years of the project, which was called "It's Legit II" locally, as it followed an earlier CAE project known as "It's Legit". Fall Term of the first school year (2015-16) of It's Legit II, was needed for hiring and training project staff, developing informed consents and obtaining approval from the University of Oregon's Institutional Review Board, and meeting with public school teachers to set up the schedules and plan for implementation. The lessons in the schools were provided between January and June of 2016. Pre- and post-intervention surveys were completed by 988 students from eight middle schools. The age of participating students ranged from 12 to 15 years old, with the average age being 14 (standard deviation, $\mathrm{SD}=0.5$ ). Slightly over half the respondents were female (52\%). The second year of the project, 2016-17, lessons 
started Fall Term and continued throughout the year, with different classes participating different terms. Students from 9 middle schools participated, including Gardiner, West Orient, Dexter McCarty, Damascus, Clear Creek, Ogden, Gordon Russell, Colton, and Baker Prairie. The number of middle school students who responded to both pre- and post-intervention surveys that could be matched on confidential codes, in accord with an approved Institutional Review Board (IRB) protocol, was 1223. More students were provided with the intervention but did not complete both surveys, perhaps due to being absent either when the pre-intervention survey was given (115 students had no pre-intervention data) or when the post-intervention survey was given (128 had no post intervention data) or both times (61 had neither pre- nor post-intervention data). This indicates that 1528 students were served the second year of the project and $80 \%$ responded to both pre- and post-intervention surveys. Participation was voluntary. Age ranged from 12 to 15 years old, with the average age being 13. About half of the respondents were female (51\%).

The survey asked about Hispanic/Latino ethnicity separately from race, and before asking about race. In 2015-16, of those who responded to this question, $25.3 \%$ were Hispanic and these could be of any race. In 2016-17, 26\% were Hispanic. The list below shows the response options for the question about race followed by the percentage selecting that option the 1st and then the 2nd year of the study:

- Two or more races, $28.3,28.0$

- American Indian, 4.3, 6.1

- Asian, 2.7, 2.9

- African American, 2.0, 2.4

- Hawaiian or other Pacific Islander, 1.5, 1.7

- White, $61.3,85.8$

\section{Results}

Each year of the project, responses to pre- and post-intervention survey items were compared. Paired samples t-tests were used to determine if statistically significant changes occurred. In this section, items with significant changes $(p<$ 0.001 ) both years are listed, along with their pre- and post-intervention mean/ average and standard deviation (SD).

- I know what my goals are. 1) Agree, 2) Disagree

1st Year:

Pre-intervention mean $(\mathrm{SD})=1.19(0.40)$

Post-intervention mean $(\mathrm{SD})=1.13(0.33)$

2nd Year:

Pre-intervention average $(\mathrm{SD})=1.16(0.37)$

Post-intervention average $(\mathrm{SD})=1.12(0.32)$

- Here are some questions about things that people your age might talk to a parent or guardian about. Mark one answer for each topic that best describes when or if you have talked to a parent or guardian about that topic: Topic: 


\section{Abstinence}

Response Options: 1) Never, 2) Some time ago (more than 2 months ago), 3) About a month or two ago, 4) Recently, this week or a few weeks ago

1st Year:

Pre-intervention mean $(\mathrm{SD})=1.78(1.02)$

Post-intervention mean $(\mathrm{SD})=2.08(1.18)$

2nd Year:

Pre-intervention average $(\mathrm{SD})=1.71(0.88)$

Post-intervention average $(\mathrm{SD})=2.24(1.25)$

- If I have sex, I might get HIV.

1) Strongly disagree, 2) Disagree, 3) Not sure, 4) Agree, 5) Strongly agree 1st Year:

Pre-intervention mean $(\mathrm{SD})=3.10(1.04)$

Post-intervention mean $(\mathrm{SD})=3.93(0.95)$

2nd Year:

Pre-intervention average $(\mathrm{SD})=3.06(0.98)$

Post-intervention average $(\mathrm{SD})=3.88(1.03)$

- If I have sex, I might get a sexually transmitted disease (STD).

1) Strongly disagree, 2) Disagree, 3) Not sure, 4) Agree, 5) Strongly agree 1st Year:

Pre-intervention mean $(\mathrm{SD})=3.25(1.06)$

Post-intervention mean $(\mathrm{SD})=4.11(0.86)$

2nd Year:

Pre-intervention average $(\mathrm{SD})=3.25(1.05)$

Post-intervention average $(\mathrm{SD})=4.06(0.96)$

- If I have sex during my teen years, pregnancy could occur.

1) Strongly disagree, 2) Disagree, 3) Not sure, 4) Agree, 5) Strongly agree 1st Year:

Pre-intervention mean $(\mathrm{SD})=3.67(1.04)$

Post-intervention mean $(\mathrm{SD})=4.19(0.85)$

2nd Year:

Pre-intervention average $(\mathrm{SD})=3.67(1.06)$

Post-intervention average $(\mathrm{SD})=4.16(0.91)$

- If I do not have sex during my teen years, my parent(s) or guardian(s) will be proud of me. 1) Strongly disagree, 2) Disagree, 3) Not sure, 4) Agree, 5) Strongly agree

1st Year:

Pre-intervention mean $(\mathrm{SD})=4.01(1.03)$

Post-intervention mean $(\mathrm{SD})=4.18(0.95)$

2nd Year:

Pre-intervention average $(\mathrm{SD})=3.99(1.02)$

Post-intervention average $(\mathrm{SD})=4.13(1.02)$

- If I do not have sex during my teen years, I will be proud of myself. 
1) Strongly disagree, 2) Disagree, 3) Not sure, 4) Agree, 5) Strongly agree 1st Year:

Pre-intervention mean $(\mathrm{SD})=3.81(1.07)$

Post-intervention mean $(\mathrm{SD})=4.03(1.01)$

2nd Year:

Pre-intervention average $(\mathrm{SD})=3.84(1.07)$

Post-intervention average $(\mathrm{SD})=4.03(1.01)$

- Not having sex will help me further my education.

1) Strongly disagree, 2) Disagree, 3) Not sure, 4) Agree, 5) Strongly agree 1st Year:

Pre-intervention mean $(\mathrm{SD})=3.62(2.14)$

Post-intervention mean $(\mathrm{SD})=4.04(1.04)$

2nd Year:

Pre-intervention average $(\mathrm{SD})=3.65$ (1.12)

Post-intervention average $(\mathrm{SD})=4.13$ (1.02)

- Not having sex will help me focus on getting a good job.

1) Strongly disagree, 2) Disagree, 3) Not sure, 4) Agree, 5) Strongly agree 1st Year:

Pre-intervention mean $(\mathrm{SD})=3.46(1.15)$

Post-intervention mean $(\mathrm{SD})=4.01(1.05)$

2nd Year:

Pre-intervention average $(\mathrm{SD})=3.56(1.12)$

Post-intervention average $(\mathrm{SD})=4.06(1.04)$

- If you feel healthy, you don't have an STD.

Note that although the change in the mean for this item was statistically significant $(p<0.001)$ both years, it was only in Year 2 that the change in which response options were selected reflected the actual teaching of the program. It this item is revised for future surveys, it would be better to code "Don't know" as zero than as three or to just not include that option. The correct answer is "false" (see

http://www.webmd.com/sexual-conditions/features/could-you-have-std-not-kn ow\#1)

1st Year:

Pre-intervention mean $(\mathrm{SD})=2.45(0.65)$

1) True $53 \%, 2$ ) False $7.2 \%, 3$ ) Not sure $39.8 \%$

Post-intervention mean (SD) $=1.30(0.67)$

1) True $82.4 \%, 2$ ) False $5.1 \%, 3)$ Not sure $12.5 \%$

2nd Year:

Pre-intervention average $(\mathrm{SD})=2.45(0.67)$

1) True $10.0 \%, 2)$ False $34.9 \%, 3)$ Not sure $55.1 \%$

Post-intervention average $(\mathrm{SD})=2.13(0.46)$

1) True $5.4 \%, 2$ ) False $77.0 \%, 3)$ Not sure $17.6 \%$

- If a person has an STD, the person's sexual partner probably has it too.

1st Year: 
Pre-intervention mean $(\mathrm{SD})=1.87(0.96)$

1) True $53 \%$, 2) False $7.2 \%, 3$ ) Not sure $39.8 \%$

Post-intervention mean $(\mathrm{SD})=1.30(0.67)$

1) True $82.4 \%, 2$ ) False $5.1 \%, 3$ ) Not sure $12.5 \%$

2nd Year:

Pre-intervention average $(\mathrm{SD})=1.88(0.96)$

1) True $53.4 \%, 2$ ) False $6.3 \%, 3)$ Not sure $40.7 \%$

Post-intervention average $(\mathrm{SD})=1.29(0.68)$

1) True $83.5 \%, 2$ ) False $3.4 \%, 3$ ) Not sure $13.1 \%$

Discussion

Were the Objectives Achieved?

The first four objectives of this project were clearly met and the fifth one, which will be discussed in more detail below, if used in the future for other projects, should be re-worded to take into account initial status of participants.

Objective 1: Public school health teachers and NWFS staff will provide the Promoting Health Among Teens! [PHAT] Abstinence-Only, School Edition (Jemmott et al., 2014) curriculum for participating middle school students. This objective was achieved. Project leaders from the community agency and teachers in the schools worked well together. The fact that a 9th school asked to join the project the second year speaks well for the reputation of the project in the community.

Objective 2: Public school classroom teachers will provide sections of the Promoting Health Among Teens! Abstinence-Only, School Edition (Jemmott et al., 2014) curriculum for participating middle school students that include lessons with information on reproductive anatomy, fetal development, and STI prevention information. This objective was achieved.

Objective 3: Public school health teachers and NWFS staff will provide the Promoting Health Among Teens! Abstinence-Only, School Edition (Jemmott et al., 2014) curriculum for participating middle school students with effective lessons related to abstinence during the academic school years of the project to heighten perception of risk for HIV/STI and unplanned pregnancy. The effectiveness of these lessons will be measured using the pre- and post-intervention survey items about perceptions of risk for HIV/STI and unplanned pregnancy:

- If I have sex, I might get HIV.

- If I have sex, I might get a sexually transmitted disease (STD).

- If I have sex during my teen years, pregnancy could occur.

This objective was achieved. We expected to see a statistically significant change $(p<0.05)$, indicating increased perception of risk. For all three of these, a very statistically significant change $(p=0.001)$ occurred both years.

Objective 4: Public school health teachers and NWFS staff will provide the Promoting Health Among Teens! curriculum for participating middle school students with effective lessons related to abstinence during the academic school years of the project to bolster positive attitudes and beliefs regarding abstinence. The effectiveness of these lessons will be measured through the survey which we 
expect to show a statistically significant $(p<0.05)$ post-intervention change in the average scores on items related to benefits of being abstinent, specifically:

- If I do not have sex, my parents will be proud of me.

- If I do not have sex during my teenage years, I will be proud of myself.

- Not having sex will help me further my education.

- Not having sex will help me focus on getting a good job.

This objective was achieved. We expected to see a statistically significant change $(p<0.05)$, indicating increased perception of risk. For all four of these, a very statistically significant change $(p=0.001)$ occurred both years.

Objective 5: Public school health teachers, NWFS staff, and peer leaders will effectively provide the Promoting Health Among Teens! adapted curriculum for participating middle school students during the academic school years of the project so that stronger intentions to practice abstinence will be developed. This will be measured through the survey showing a statistically significant $(p<0.05)$ post-intervention change in the average scores on items related to intentions to practice abstinence:

- How likely is it that you will decide to have sexual intercourse within the next 3 months? 1) Very Unlikely, 2) Unlikely, 3) Not sure, 4) Likely, 5) Very Likely.

Most of the students ( $82 \%$ in the 1 st year and $86 \%$ in the 2 nd year) already thought it was "Unlikely" or "Very Unlikely" when asked before the intervention. After the intervention, in the 1 st year, $83 \%$ thought it was "Unlikely" or "Very Unlikely" and $86 \%$ had the same perception in the 2 nd year. This was a positive outcome, although not a statistically significant $(p<0.05)$ change. This project did not have a control group but other studies with control groups have shown that interventions to protect, support, and encourage initial positive attitudes are successful if the high initial percentage that is maintained, even when an increase does not occur. This is because, as youth get older, even over a few months at this critical time in their lives, if there is no intervention, the number of youth who start taking changes with risky behaviors increases. Thus, when a control group is compared to an intervention group, often the scores of the control group will deteriorate and success for the intervention group is to avoid that.

- I will not have sex in the next 3 months.

How much do you agree or disagree? Strongly Disagree $=1$; Disagree $=2$; In the Middle = 3; Agree $=4$; Strongly Agree $=5$

Before the intervention, in the 1st year, the average response was 4.38. After the intervention, it was 4.43 . In the 2 nd year, the average response was 4.43 and afterwards, it was 4.44 . Although not a statistically significant $(p<0.05)$ changes, these were positive outcomes, indicating that the intervention probably helped maintain positive attitudes. Most of the youth already were strongly in favor of abstinence, creating a "ceiling" effect. The intervention provided encouragement for the students with positive attitudes. Averages probably would have gone down for a control group in a research project with an equivalent, randomly assigned, control group. However, research with control groups is expensive and 
often, schools are not interested in participating in that type of research where a group of students do not receive what is expected to be a worthwhile intervention, just to show that they will do worse than other students who do receive the intervention.

In situations like this, instead of using wording in objectives that just says "stronger intentions to practice abstinence will be developed" it would be better to add "or, if initial intentions to abstain are already high, these high intentions will be maintained".

\section{Conclusion}

The outcomes of both years of the It's Legit II: Promoting Health Among Teens! Project indicated that it was implemented well, received well, and had a beneficial effect. This evaluation indicates that projects like this should continue to be supported and promoted.

\section{Acknowledgements}

This evaluation was supported by Competitive Abstinence Education (CAE) grant 90AR0032-01-00 offered by Administration for Children and Families (ACF), Administration on Children, Youth and Families (ACYF), and Family and Youth Services Bureau (FYSB) of the U.S. Department of Health and Human Services (DHHS), which was awarded to Northwest Family Services, a nonprofit organization in Portland, Oregon. The content is solely the responsibility of the author and does not necessarily represent the official views of ACF, ACYF, FYSB, or DHHS.

\section{References}

Ajzen, I., \& Fishbein, M. (2005). The Influence of Attitudes on Behavior. In D. Albarracin, B. T. Johnson, \& M. P. Zanna (Eds.), The Handbook of Attitudes (pp. 173-221). Mahwah, NJ: Erlbaum.

Bandura, A. (1977). Social Learning Theory. Englewood Cliffs, NJ: Prentice Hall.

Bandura, A. (1997). Self-Efficacy: The Exercise of Control. New York: Freeman.

Bandura, A. (2004). Health Promotion by Social Cognitive Means. Health Education \& Behavior, 31, 143-164. https://doi.org/10.1177/1090198104263660

Child Trends DataBank (2017). Sexually Experienced Teens. Washington, DC: Author. Retrieved from https://www.childtrends.org/indicators/sexually-experienced-teens/

DeGaston, J. F., Jensen, L., Weed, S.E., \& Tanas, R. (1994). Teacher Philosophy and Program Implementation and the Impact of Sex Education Outcomes. Journal of Research and Development in Education, 27, 265-270.

Ferraro, K. F., \& Pressler, K. A. (2011). Do Abstinence Education Programs Influence High-School Academic Performance? Journal of Health Studies, 26, 230-235.

Fishbein, M. (2008). A Reasoned Action Approach to Health Promotion. Medical Decision Making, 28, 834-844. https://doi.org/10.1177/0272989X08326092

Fuller, R., \& Bankston, C. (2002). Peer Leader Training: A Youth Solutions Manual. Portland, OR: Northwest Family Services. 
Goesling, B., Colman, S., Trenholm, C., Terzian, M., \& Moore, K. (2014). Programs to Reduce Teen Pregnancy, Sexually Transmitted Infections, and Associated Sexual Risk Behaviors: A Systematic Review. Journal of Adolescent Health, 54, 499-507. https://doi.org/10.1016/j.jadohealth.2013.12.004

Hartman, T. (2009). Action Theory, Theory of Planned Behavior, and Media Choice. In T. Hartman (Ed.), Media Choice: A Theoretical and Empirical Overview (pp. 32-52). New York: Routledge, Taylor \& Francis Group.

Jemmott, J. B., III, Jemmott, L. S., \& Fong, G. T. (2010). Efficacy of a Theory-Based Abstinence-Only Intervention over 24 Months: A Randomized Controlled Trial with Young Adolescents. Archives of Pediatrics and Adolescent Medicine, 164, 152-159, [Online] Available: http://jamanetwork.com/journals/jamapediatrics/fullarticle/382798 (October 2, 2017) https://doi.org/10.1001/archpediatrics.2009.267

Jemmott, L. S., Jemmott, J. B. III, \& McCaffree, K. (2014). Promoting Health among Teens (School ed.)! Abstinence-Only Intervention, New York, NY: Select Media.

Office of Adolescent Pregnancy (2016). Trends in Teen Pregnancy and Childbirth. Washington DC: Author.

https://www.hhs.gov/ash/oah/adolescent-development/reproductive-health-and-teen-p regnancy/teen-pregnancy-and-childbearing/trends/index.html

Romano, J. L., \& Netland, J. D. (2008). The Application of the Theory of Reasoned Action and Planned Behavior to Prevention Science in Counseling Psychology. The Counseling Psychologist, 36, 777-806. https://doi.org/10.1177/0011000007301670

Roth, S. (2015). Report: Oregon Has Worst Graduation Rate in the US. http://www.krem.com/story/news/education/2015/05/14/report-oregon-has-worst-gra duation-rate-in-the-us/27292623/

Smith, T. E., Panisch, L. S., Malespin, T., \& Pereira, M. G. (2017). Evaluating the Effectiveness of Abstinence Education. Journal of Evidence-Informed Social Work, 14, 360-367. https://doi.org/10.1080/23761407.2017.1340860

Terry, L. (2017). By the Numbers: Sexually Transmitted Diseases in Oregon. The Oregonian/Oregon Live.

http://www.oregonlive.com/health/index.ssf/2017/07/by_the_numbers_sexually_trans $\underline{\text { m.html }}$

Vincent, C. G., Xue, L., Tobin, T. J., \& Fuller, R. (2011). A Psychometric Evaluation of the Core Baseline Questionnaire Used in the Oregon Youth Development Project. http://pages.uoregon.edu/ttobin/OAPPpsy.pdf 